\title{
SISTEM PENDUKUNG KEPUTUSAN DALAM PENENTUAN MITRA JASA PENGIRIMAN BARANG TERBAIK DI KOTA KISARAN MENGGUNAKAN METODE TOPSIS
}

\author{
Risnawati ${ }^{*}$, Nuriadi Manurung ${ }^{1}$ \\ Sistem Komputer, STMIK Royal Kisaran \\ *email: rhisnawati716@gmail.com
}

\begin{abstract}
The development of the freight forwarding service industry has increased quite rapidly. The era of globalization requires people to have high mobility. Since the enactment of the free market in Indonesia, opening up the trade flow of goods or services has become unlimited. The need for freight forwarding services is increasing to meet people's needs. The number of goods delivery service partners makes it difficult for the community to choose and determine the best freight forwarding partners. The increasingly fierce competition conditions, making every company must be able to survive, even must be able to continue to grow. One important thing that needs to be done and considered by every company to be able to survive and develop is to maintain the quality of service to the consumer's satisfaction. In choosing the best freight forwarding partner, a mechanism is needed to be able to deliver goods that are truly feasible. One of them can be done using the Decision Support System using the TOPSIS method. based on predetermined criteria which will be considered to be the best partner in the delivery of goods services in Kota Kisaran based on the concept by comparing existing alternatives such as JNE, TIKI, Post Office Indonesia, J \& T, and Indah Cargo. Based on each criterion by determining the value of the weight taken from the appropriate research from the object that has been determined
\end{abstract}

Keywords: Decision Support System, Topsis Method, Freight Forwarding Partner

\begin{abstract}
Abstrak: Perkembangan industri jasa pengiriman barang mengalami peningkatan yang cukup pesat. Era globalisasi menuntut manusia untuk memiliki mobilitas yang tinggi. Sejak diberlakukannya pasar bebas di Indonesia, membuka arus perdagangan barang atau jasa menjadi tidak terbatas. Kebutuhan akan jasa pengiriman barang semakin meningkat untuk memenuhi kebutuhan masyarakat. Banyaknya mitra jasa pengiriman barang membuat para masyarakat sulit dalam memilih dan menentukan mitra jasa pengiriman barang yang paling baik. Kondisi persaingan yang semakin ketat, membuat setiap perusahaan harus mampu bertahan hidup, bahkan harus dapat terus berkembang. Salah satu hal penting yang perlu dilakukan dan diperhatikan oleh setiap perusahaan untuk dapat bertahan hidup dan berkembang adalah mempertahankan kualitas layanan terhadap kepuasaaan konsumen. Dalam pemilihan mitra jasa pengiriman barang yang terbaik diperlukan mekanisme untuk dapat mengirimkan barang yang benar-benar layak. Salah satunya dapat dilakukan dengan menggunakan Sistem Pendukung Keputusan dengan metode TOPSIS. berdasarkan kriteria yang sudah ditentukan yang akan dianggap menjadi mitra jasa pengiriman barang terbaik di Kota Kisaran berdasarkan konsep dengan membandingkan alternatif-alternatif yang ada seperti JNE, TIKI, Kantor Pos Indonesia, J\&T, dan Indah Cargo. Berdasarkan setiap kriteria dengan menentukan nilai bobot yang diambil dari penelitian yang sesuai dari objek yang sudah ditentukan
\end{abstract}

Kata Kunci : Sistem Pendukung Keputusan, Metode Topsis, Mitra Jasa Pengiriman Barang 
DOI: https://doi.org/10.33330/jurteksi.v5i2.357

Available online at http://jurnal.stmikroyal.ac.id/index.php/jurteksi

\section{PENDAHULUAN}

Saat ini perkembangan industri jasa pengiriman barang mengalami peningkatan yang cukup pesat. Era globalisasi menuntut manusia untuk memiliki mobilitas yang tinggi. Sejak diberlakukannya pasar bebas di Indonesia, membuka arus perdagangan barang atau jasa menjadi tidak terbatas. Kebutuhan akan jasa pengiriman barang semakin meningkat untuk memenuhi kebutuhan masyarakat.

Jasa juga merupakan suatu aktivitas maupun manfaat dan apapun yang ditawarkan oleh satu pihak kepada pihak lain, yang pada dasarnya tanpa wujud dan tidak menghasilkan kepemilikan apapun seperti produk, karena jasa sifatnya adalah tidak terlihat, tetapi berupa pemberian bantuan dalam pemuasan kebutuhan dan keinginan pelanggan dengan atau tanpa imbalan tertentu sebagai timbal baliknya. Yang menjadikan pengiriman barang ini banyak di minati oleh masyarakat pada saat di era masa kini [1].

Jasa juga di anggap sebagai tindakan atau kegiatan ekonomi yang menciptakan dan memberi manfaat bagi pelanggan pada waktu dan tempat tertentu, sebagai hasil dari tindakan yang mewujudkan perubahan yang diinginkan dalam diri atau atas nama penerima jasa tersebut. Sedangkan manfaat yang dimaksud adalah keuntungan atau laba yang diperoleh pelanggan dari kinerja jasa atau barang fisik [2].

Banyaknya mitra jasa pengiriman barang membuat para masyarakat sulit dalam memilih dan menentukan mitra jasa pengiriman barang yang paling baik, agar mereka dapat mengirimkan barang kiriman mereka dengan aman sampai tujuan yang diinginkan tanpa ada kendala apapun yang kemungkinan bisa saja ter- jadi. Kondisi persaingan yang semakin ketat, membuat setiap perusahaan harus mampu bertahan hidup, bahkan harus dapat terus berkembang. Salah satu hal penting yang perlu dilakukan dan diperhatikan oleh setiap perusahaan untuk dapat bertahan hidup dan berkembang adalah mempertahankan kualitas layanan terhadap kepuasaaan konsumen perusahaan. Kualitas layanan memang menjadi salah satu persoalan yang harus dipantau secara terus menerus oleh setiap perusahaan jasa.

Kualitas pelayanan adalah tingkat keunggulan yang diharapkan dan pengendalian atas tingkat keunggulan tersebut untuk memenuhi keinginan pelanggan. Kualitas layanan merupakan hal yang sangat penting untuk perusahaan jasa, untuk mempertahankan kualitas layanan perusahaan jasa harus senantiasa melakukan survei dari waktu ke waktu kepada konsumen untuk mengetahui apa yang diinginkan dan diharapkan terhadap perusahaan jasa selaku penyedia layanan [3].

Dalam pemilihan mitra jasa pengiriman barang yang terbaik diperlukan mekanisme untuk dapat mengirimkan barang yang benar-benar layak. Salah satunya dapat dilakukan dengan menggunakan Sistem Pendukung Keputusan dengan metode TOPSIS (Techinique for Order Preference by Similarity to Ideal Solution). Dalam hal ini hampir sama dengan hasil penelitian tujuannya adalah untuk menentukan sekolah terbaik dan layak pada Kecamatan Kisaran Timur dan Kecamatan Kisaran Barat [4].

Metode TOPSIS (Techinique for Order Preference by Similarity to Ideal Solution) merupakan salah satu metode pada Sistem Pendukung Keputusan (SPK). Melalui penerapan metode ini, peneliti dapat membandingkan setiap mi- 
tra jasa pengiriman barang yang satu dengan yang lainnya berdasarkan kriteria yang sudah ditentukan yang akan dianggap menjadi mitra jasa pengiriman barang terbaik di Kota Kisaran berdasarkan konsep dengan memban-dingkan alternatif-alternatif yang ada seperti JNE, TIKI, Kantor Pos Indonesia, J\&T, dan Indah Cargo. Berdasarkan setiap kriteria dengan menentukan nilai bobot yang diambil dari penelitian yang sesuai dari objek yang sudah ditentukan.

\section{METODE}

TOPSIS didasarkan pada konsep dimana alternatif terpilih yang terbaik tidak hanya memiliki jarak terpendek dari solusi ideal positif, namun juga memiliki jarak terpanjang dari solusi ideal negatif. Konsep ini banyak digunakan pada beberapa model MADM untuk menyelesaikan masalah keputusan secara praktis. Hal ini disebabkan konsepnya sederhana dan mudah dipahami, komputasinya efisien, dan memiliki kemampuan untuk mengukur kinerja relatif dari alternatif-alternatif keputusan dalam bentuk matematis yang sederhana.

Secara umum, prosedur TOPSIS mengikuti langkah-langkah sebagai berikut:

a. Menghitung nilai normalisasi;

$$
\mathrm{r}_{\mathrm{ij}}=\frac{x_{i j}}{\sqrt{\sum_{i=1}^{m} x_{i j}{ }^{2}}} ;
$$

b. Menghitung nilai normalisasi terbobot;

$$
\boldsymbol{Y} \boldsymbol{i j}=W \boldsymbol{i} \times \boldsymbol{r i j}
$$

c. Menentukan matriks solusi ideal positif dan matriks solusi ideal negatif;

$$
\begin{aligned}
& \mathrm{A}^{+}=\left(Y_{1}^{+}, Y_{2}^{+}, Y_{3}^{+}, \ldots, Y_{n}^{n}\right) ; \\
& \mathrm{A}^{-}=\left(Y_{1}^{-}, Y_{2}^{-}, Y_{3}^{-}, \ldots, Y_{n}^{n}\right) ; \\
& Y_{J}^{+}=\left\{\begin{array}{c}
\max Y_{i j} \\
i \\
\min Y_{i j} \\
i
\end{array}\right.
\end{aligned}
$$

d. Menentukan jarak antara nilai setiap alternatif dengan matriks solusi ideal positif dan matriks solusi ideal negatif;

$$
\mathrm{D}_{\mathrm{i}}^{+}=\sqrt{\sum_{i=1}^{n}\left(y_{i}^{+}-y_{i j}\right)^{2}}
$$

Jarak ideal solusi negatif

$$
\mathrm{D}_{\mathrm{i}}^{-} \sqrt{\sum_{j=1}^{n}\left(y_{i j}-y_{i}^{-}\right)^{2}}
$$

e. Menentukan nilai preferensi untuk setiap alternatif.

$$
\mathrm{Vi}=\frac{D_{i}^{-}}{D_{i}^{-}+D_{i}^{+}}
$$

\section{HASIL DAN PEMBAHASAN}

Dalam proses penentuan Mitra Jasa Pengiriman Barang terbaik yang dilakukan dengan menggunakan metode TOPSIS, dan kriteria-kriteria yang dubutuhkan didapat dari Perusahaan Masing-masing Mitra Jasa, bobot kepentingan setiap kriteria dan rating kecocokan alternatif terhadap kriteria untuk melakukan perhitungan sehingga akan didapatkan alternatif terbaik.

Untuk mengetahui mitra jasa pengiriman barang terbaik, maka alternatif yang dipilih ada 5 antara lain 1 . POS Indonesia (A01), 2. JNE (A02), 3. 
DOI: https://doi.org/10.33330/jurteksi.v5i2.357

Available online at http://jurnal.stmikroyal.ac.id/index.php/jurteksi

TIKI (A03), 4. J\&T (A04), 5. Indah Cargo (A05), Dan kriteria yang digunakan antara lain 1. Biaya Pengiriman (C01), 2. Keamanan Barang (C02), 3. Ketepatan Waktu (C03), 4. Pengalaman Perusahaan (C04).

Tabel 1. Bobot Kriteria SMA

\begin{tabular}{ccl}
\hline $\begin{array}{c}\text { Kode } \\
\text { Kriteria }\end{array}$ & $\begin{array}{c}\text { Bobot } \\
\text { Kriteria }\end{array}$ & \multicolumn{1}{c}{ Nama Kriteria } \\
\hline $\mathrm{C}_{01}$ & 3 & Biaya Pengiriman \\
\hline $\mathrm{C}_{02}$ & 5 & Keamanan Barang \\
\hline $\mathrm{C}_{03}$ & 5 & Ketepatan Waktu \\
\hline $\mathrm{C}_{04}$ & 4 & Pengalaman Perusahaan \\
\hline
\end{tabular}

Tabel 2. Nilai Alternatif SMA

\begin{tabular}{lllll}
\hline Kode Alternatif & \multicolumn{4}{l}{ Kode Kriteria } \\
\cline { 2 - 5 } & $\mathbf{C}_{\mathbf{0 1}}$ & $\mathbf{C}_{\mathbf{0 2}}$ & $\mathbf{C}_{\mathbf{0 3}}$ & $\mathbf{C}_{\mathbf{0 4}}$ \\
\hline $\mathrm{A}_{01}$ & 3 & 4 & 3 & 5 \\
\hline $\mathrm{A}_{02}$ & 3 & 4 & 4 & 5 \\
\hline $\mathrm{A}_{03}$ & 3 & 3 & 3 & 4 \\
\hline $\mathrm{A}_{04}$ & 2 & 5 & 4 & 2 \\
\hline $\mathrm{A}_{05}$ & 2 & 3 & 3 & 3 \\
\hline & & & & \\
& & & & \\
& & & &
\end{tabular}

Tabel 3. Normalisasi Dari Setiap Alternatif Pada Setiap Kriteria

\begin{tabular}{ccccc}
\hline \multirow{2}{*}{ Kode Alternatif } & \multicolumn{5}{c}{ Kode Kriteria } \\
\cline { 2 - 5 } & $\mathbf{C}_{\mathbf{0 1}}$ & $\mathbf{C}_{\mathbf{0 2}}$ & $\mathbf{C}_{\mathbf{0 3}}$ & $\mathbf{C}_{\mathbf{0 4}}$ \\
\hline $\mathrm{A}_{01}$ & 0,507093 & 0,4618802 & 0,404520 & 0,562544 \\
\hline $\mathrm{A}_{02}$ & 0,507093 & 0,4618802 & 0,539360 & 0,562544 \\
\hline $\mathrm{A}_{03}$ & 0,507093 & 0,3464102 & 0,404520 & 0,450035 \\
\hline $\mathrm{A}_{04}$ & 0,338062 & 0,5773503 & 0,539360 & 0,225018 \\
\hline $\mathrm{A}_{05}$ & 0,338062 & 0,3464102 & 0,404520 & 0,337526 \\
\hline & & & &
\end{tabular}

Tabel 4. Matriks Normalisasi Terbobot

\begin{tabular}{|c|c|c|c|c|}
\hline \multirow[t]{2}{*}{ Kode Alternatif } & \multicolumn{4}{|c|}{ Kode Kriteria } \\
\hline & $\mathrm{C}_{01}$ & $\mathrm{C}_{02}$ & $\mathrm{C}_{03}$ & $\mathrm{C}_{04}$ \\
\hline $\mathrm{A}_{01}$ & 1,521278 & 2,309401 & 2,022600 & 2,250176 \\
\hline $\mathrm{A}_{02}$ & 1,521278 & 2,309401 & 2,696799 & 2,250176 \\
\hline $\mathrm{A}_{03}$ & 1,521278 & 1,732051 & 2,022600 & 1,800141 \\
\hline $\mathrm{A}_{04}$ & 1,014185 & 2,886751 & 2,696799 & 0,90007 \\
\hline $\mathrm{A}_{05}$ & 1,014185 & 1,732051 & 2,022600 & 1,350105 \\
\hline
\end{tabular}

dan minimal berdasarkan tabel 4 untuk solusi ideal negatif sebagai berikut: 
1. Nilai $\mathrm{D}^{+}$dan $\mathrm{D}^{-}$dari $\mathrm{A} 01$

$$
\begin{aligned}
& D_{x}^{+}=\sqrt{(1,521278-1,521278)} 2+ \\
& (2,309401-2,886751) 2+ \\
& (2,022600-2,696799) 2+ \\
& (0,562544-0,562544) 2 \\
& =0,57735
\end{aligned}
$$

$D_{x}^{-}=\sqrt{(1,521278-1,014185)} 2+$ $(2,309401-1,732051) 2+$ $(2,022600-2,022600) 2+$ $(0,562544-0,225018) 2$ $=0,668773$

2. Nilai $\mathrm{D}^{+}$dan $\mathrm{D}^{-}$dari $\mathrm{A} 02$

$D_{x}^{+}=$ $\sqrt{(1,521278-1,232992)} 2+$ $(2,309401-2,886751) 2+$ $(2,696799-2,696799) 2+$ $(0,562544-0,562544) 2^{2}$ 0,577735

$$
\begin{aligned}
& \quad D_{x}^{-}= \\
& \sqrt{(1,521278-1,014185) 2}+ \\
& (2,309401-1,732051) 2+ \\
& (2,696799-2,022600) 2+ \\
& (0,562544-0,225018) 2 \\
& =1,076543
\end{aligned}
$$

3. Nilai $\mathrm{D}^{+}$dan $\mathrm{D}^{-}$dari $\mathrm{A} 03$

$$
D_{x}^{+}=\sqrt{(1,521278-1,521278)} 2+
$$$$
(1,732051-2,886751) 2+
$$$$
(2,022600-2,696799) 2+
$$$$
(2,022600-2,022600) 2
$$$$
=1,337115
$$

$$
D_{x}^{-}=\sqrt{(1,521278-1,014185)} 2+
$$$$
(1,732051-1,732051) 2+
$$$$
(2,022600-2,022600) 2+
$$$$
(2,022600-0,225018) 2
$$$$
=1,867738
$$

4. Nilai $\mathrm{D}^{+}$dan $\mathrm{D}^{-}$dari A04

$$
\begin{aligned}
& D_{x}^{+}=\sqrt{(1.014185-1.521278)} 2+ \\
& (2.886751-2.886751) 2+ \\
& (2.696799-2.696799) 2+ \\
& (0.225018-0.562544) 2^{2} \\
& =0,609153 \\
& D_{x}^{-}=\sqrt{(1,014185-1,014185)} 2+ \\
& (2,886751-1,732051) 2+ \\
& (2,696799-2,022600) 2+ \\
& (0,225018-0,225018) 2 \\
& =1,337115
\end{aligned}
$$

5. Nilai $\mathrm{D}^{+}$dan $\mathrm{D}^{-}$dari $\mathrm{A} 05$

$$
\begin{gathered}
D_{x}^{+}=\sqrt{(1,014085-1,521278)} 2 \\
+(1,732051 \\
-2,886751) 2 \\
+(2,022600 \\
-2,696799) 2 \\
+(0,334526 \\
-0,562544) \\
=1,447672 \quad \\
D_{x}^{-}=\sqrt{(1,014085-1,014185) 2}+ \\
(1,732051-1,732051) 2+ \\
(2,022600-2,022600) 2+ \\
(0,337526-0,225018) 2 \\
=0,112508
\end{gathered}
$$

Hasil perhitungan di atas kemudian disusun kedalam tabel Nilai $\mathrm{D}^{+}$dan $\mathrm{D}^{-}$ sebagai berikut:

Tabel 5. Nilai $\mathrm{D}^{+}$dan $\mathrm{D}^{-}$

\begin{tabular}{ccc}
\hline Kode Alternatif & $\mathbf{D}^{+}$ & $\mathbf{D}^{-}$ \\
\hline $\mathrm{A}_{01}$ & 0,817785 & 0,668773 \\
\hline $\mathrm{A}_{02}$ & 1,037566 & 1,076543 \\
\hline $\mathrm{A}_{03}$ & 1,129450 & 1,275658 \\
\hline $\mathrm{A}_{04}$ & 1,156337 & 1,337115 \\
\hline $\mathrm{A}_{05}$ & 0,335422 & 0,112508 \\
\hline
\end{tabular}

Langkah berikutnya yaitu menentukan nilai preferensi tabel 5 untuk mendapatkan urutan rangking tertinggi. Seperti tabel berikut: 
DOI: https://doi.org/10.33330/jurteksi.v5i2.357

Available online at http://jurnal.stmikroyal.ac.id/index.php/jurteksi

Tabel 6. Preferensi dan Rangking Alternatif

\begin{tabular}{ccc}
\hline $\begin{array}{c}\text { Kode } \\
\text { Alternatif }\end{array}$ & Preferensi & Rangking \\
\hline $\mathrm{A}_{01}$ & 0,44988 & 4 \\
\hline $\mathrm{A}_{02}$ & 0,883463 & 1 \\
\hline $\mathrm{A}_{03}$ & 0,530395 & 3 \\
\hline $\mathrm{A}_{04}$ & 0,536251 & 2 \\
\hline $\mathrm{A}_{05}$ & 0,251173 & 5 \\
\hline
\end{tabular}

Dari tabel 6 maka dihasilkan perhitungan preferensi sehingga dapat diketahui bahwa Mitra Jasa Pengiriman Barang terbaik adalah pada kode A02 sebagai peringkat tertinggi dengan nilai 0,883463 , peringkat 2 A04 $=0,536251$, peringkat $3 \mathrm{~A} 03=0,530395$, peringkat 4 $\mathrm{A} 01=0,44988$, peringkat $5 \mathrm{~A} 05=$ 0,251173 .

\section{SIMPULAN}

Dari pembahasan penelitian yang telah dilakukan, maka kesimpulan pada penelitian ini adalah:

1. Metode TOPSIS diterapkan dalam sistem pendukung keputusan untuk menghitung dan memberikan penilaian yang telah dirangkingkan sehingga dapat menentukan mitra jasa pengiriman barang terbaik dengan tepat.
2. Sistem pendukung keputusan ini dapat dijadikan referensi bagi pihak perusahaan untuk membantu para masyarakat dalam melakukan pemilihan mitra jasa yang ada di Kota Kisaran.

\section{DAFTAR PUSTAKA}

[1] Kotler. 2018. Manajemen Pemasaran, Jilid 1, Edisi 13, Erlangga.

[2] Lovelock, Wright. 2013. Analisa Tingkat Kepuasan Peanggan Terhadap Kualitas Pelayanan Jasa Pengiriman Expres, Institut Pertanian Bogor.

[3] Tjiptono. 2006. Manajemen Jasa, Yogyakarta: Andi Offset

[4] Risnawati. 2018. "Sistem Pendukung Keputusan Penentuan Sekolah Menengah Atas (SMA) Terbaik Menggunakan Metode Topsis". Proceeding Seminar Nasional Royal, 2018:317-320

[5] Azhar, Zulfi. "Sistem Pendukung Keputusan Dalam Menentukan Penempatan Karyawan Baru Di Pdam Kisaran Dengan Metode Smart. "JURTEKSI 4.2 (2018): 179-184. 